\title{
Bauwerke für die Ewigkeit
}

Wir bauen große und kleine Talsperren. Na ja, eigentlich bauen wir ja gar nicht mehr so viele dieser Bauwerke. Die meisten Talsperren sind ja eh schon da! Geplant und gebaut von Ingenieurinnen und Ingenieuren in der letzten Generation und in der vorletzten Generation und dann gibt es da auch die Anlagen, die noch älter sind. All diese Talsperren sind heute noch da! All diese Staubauwerke werden auch noch da sein, wenn wir in den Ruhestand gehen. Das trifft auch für Sie, liebe Leserin bzw. lieber Leser, zu - egal ob Sie noch studieren oder sich schon auf die beste Zeit des Lebens freuen.

- Talsperren werden Teil des Flusssystems.

- Talsperren werden Teil der Landschaft.

- Talsperren können in aller Regel nicht mehr zurückgebaut werden.

- Talsperren müssen vom ersten Tag an tragsicher sein und überwacht werden.

Die Absperrbauwerke der Talsperren sind Staudämme oder Staumauern. Viele dieser Strukturen sind so klein und unauffällig, dass wir sie gar nicht als künstlich geschaffen wahrnehmen. Andere sind deutlich zu erkennen und einige dieser Bauwerke gehören zu den größten von Menschenhand geschaffenen technischen Konstruktionen. Wie bei Brücken, Hochhäusern oder anderen großen Bauwerken ist es auch bei Talsperren in der Planungsphase üblich und erforderlich, eine Lebensdauer anzunehmen bzw. zu definieren. Wichtige Nachweise zur Tragsicherheit und auch zur Dauerhaftigkeit der neu zu errichtenden Bauteile werden unter Berücksichtigung dieses Zeitraums geführt. Nach dessen Ablauf - oft aber auch bedeutend früher oder später - werden Brücken, Hochhäuser und vergleichbare Bauwerke oft abgerissen. An ihre Stelle kommt häufig zeitgemäßer Ersatz.

Bei den Talsperren ist das vollkommen anders. Diese Bauwerke stehen nicht alleine. Sie stauen den Fluss auf. Sie halten Feststoffe zurück. Sie bewirken eine massive Veränderung des Gewässersystems. Und genauso, wie Flüsse unsere Landschaften in den vergangenen Jahrtausenden durch Erosionsund Ablagerungsvorgänge grundlegend geformt haben, tun sie das weiter. Ab dem ersten Tag des Betriebs einer Talsperre arbeitet der Fluss daran, diesen neuen „Fremdkörper“ in sein Transportsystem zu integrieren. Er füllt den Stauraum mit Feststoffen auf und sein Wasser bewirkt einen Anstieg des Grundwasserspiegels. Die Abflüsse im Unterwasser werden massiv beeinflusst. Die Talflanken ändern sich. Die Vegetation passt sich an. Dieser Prozess schreitet voran - Tag für Tag und Jahr für Jahr. Die Talsperre wird sukzessive Teil des Gewässersystems.

Dies soll nun nicht die erheblichen Auswirkungen von Talsperren auf die Gewässer schönfärben. Es muss uns aber bewusst sein, dass ein Rückbau von Talsperren neben vielen anderen Gründen alleine schon wegen des Umgangs mit den großen Mengen an Feinteilen in den Stauräumen in aller Regel nicht in einer verantwortungsvollen Art und Weise möglich ist. Talsperren bleiben also! Talsperren sind daher aus unserer „kleinen“ ingenieurmäßigen Sichtweise als Bauwerke für die Ewigkeit zu sehen. In geologischen Maßstäben sieht das natürlich ganz anders aus.

Was bedeutet das für uns Talsperren-Leute?

- Talsperren müssen aus beständigen Materialien und mit nachhaltigen Konzepten errichtet werden. Die Verwendung von Baustoffen, die bereits nach wenigen Jahrzehnten am Ende ihrer Lebenszeit sind, ist nur dann möglich, wenn diese ausgewechselt, ersetzt oder saniert werden können.

- Bereits bei der Planung einer Talsperre sollten wir eine Vision haben, wie das Absperrbauwerk sicher in eine spätere Zeit geführt werden kann. So sollten wir zumindest eine grobe Vorstellung über spätere Sanierungsmöglichkeiten haben.

- Bei der Planung und der Ausführung von Talsperren sollten Sicherheiten für die Zukunft berücksichtigt werden. Breite Kronen vereinfachen spätere Sanierungen und erhöhen die Flexibilität. Ausreichende Freibordmaße geben echte Sicherheit. 
- Bei der Einschätzung der Verlandung werden insbesondere im internationalen Talsperrenbau oft Zeithorizonte von sehr wenigen Jahrzehnten gewählt. Dies ist viel zu kurz! Hier ist Weitblick erforderlich.

- Am Wichtigsten ist die Sicherheit der Talsperren! Vom ersten Tag bis in „alle Ewigkeit“ werden an jeder Talsperre Ingenieurinnen und Ingenieure mit fundiertem Fachwissen benötigt. Die Vermittlung dieses Wissens ist daher von größter Bedeutung und eine gesellschaftliche Aufgabe.

\section{Univ.-Prof. Dr.-Ing. M. Aufleger ( $ه$ )}

Arbeitsbereich Wasserbau, Institut für Infrastruktur, Universität Innsbruck, Innsbruck, Österreich

markus.aufleger@uibk.ac.at 